FACTA UNIVERSITATIS

Series: Mechanical Engineering Vol. 15, N 2, 2017, pp. 331 - 340

DOI: 10.22190/FUME170602016D

Original scientific paper

\title{
MICROSTRUCTURE AND MICROMECHANICS OF SHALE ROCKS: CASE STUDY OF MARCELLUS SHALE
}

\author{
UDC 552.5
}

\author{
Hui Du ${ }^{1}$, Kristen Carpenter ${ }^{1}$, David Hui ${ }^{2}$, Mileva Radonjic ${ }^{1}$ \\ ${ }^{1}$ Louisiana State University, Baton Rouge, LA, U.S. \\ ${ }^{2}$ The University of New Orleans, New Orleans, LA, U.S.
}

\begin{abstract}
Shale rocks play an essential role in petroleum exploration and production because they can occur either as source rocks or caprocks depending on their mineralogical composition and microstructures. More than $60 \%$ of effective seals for geologic hydrocarbon bearing formations as natural hydraulic barriers constitute of shale caprocks. The effectiveness of caprock depends on its ability to immobilize fluids, which include a low permeability and resilience to the in-situ formation of fractures as a result of pressurized injection. The alteration in sealing properties of shale rocks is directly related to the differences in their mineralogical composition and microstructure.

Failure of the shale starts with deterioration at micro/nanoscale, the structural features and properties at the micro/nanoscale can significantly impact the durability performance of these materials at the macroscale, therefore, study at micro/nanoscale becomes necessary to get better understanding of the hydraulic barriers materials to prevent failure and enhance long-term geologic storage of fluids.

Indentation tests were conducted at both micro and nanometer level on Marcellus shale samples to get the mechanical properties of bulk and individual phase of the multiphase materials. The mechanical properties map were created based on the nano indentation results and the properties of each individual phase can be correlated with bulk response in the multiphase composite; the effect of each component on the microstructure and bulk mechanical properties can be better understood.
\end{abstract}

Key Words: Shale Rock, Mechanical Properties, Indentation

Received June 02, 2017 / Accepted July 21, 2017

Corresponding author: Mileva Radonjic

Craft \& Hawkins Department of Petroleum Engineering, Louisiana State University, 127 Old Forestry Building, Baton Rouge, 70820, LA, U.S

E-mail: mileva@1su.edu 


\section{INTRODUCTION}

Shales have been a particularly interesting rock in various applications of petroleum engineering. Rock-fluid interactions have been studied in the oil industry not just in the drilling phase, but also in completion, stimulation, and enhanced oil recovery projects, for over one hundred years. Performing a correct evaluation of how a rock or formation reacts when under stresses involved for production is critical for the success of many operations.

Shales are sedimentary rocks that have distinct laminated layering characteristics and high clay and/or silt content. There are two main chemical processes responsible for these formations, with two fundamental mechanisms: 1) neoformation - precipitation from solution; and, 2) transformation - a new clay mineral inherits part of its silicate skeleton from preexisting materials such as phyllosilicate [1]. Shales are typically laminated and fissile. In order for fine clay and silt particles to form, larger organic pieces must be broken down over time and deposited in environments conducive to shale formation. The processes that break down these larger pieces into clay or silt sized particles include chemical weathering in soils, formation of authigenic minerals at the sediments depositional sit, formation of diagentic minerals after deposition, and clay minerals formed by hydrothermal alteration [1]. These variations of minerals that create the shale rock make it very vulnerable to chemical reactions. Shales are subject to phenomena such as hydration, swelling, shrinking, and strength reduction when exposed to water and ions [1].

Most of the time, the mechanisms controlling these reactions are very complex and not completely understood. They can result in a hydrophilic nature of clay particles, which is somewhat influenced by the chemical and mechanical environments the clay materials are exposed to. The chemical effects are from the intermolecular forces between clay particles and pore fluid inside the shales, typically creating an ion exchange much like an osmotic membrane. The pore water is generally much more salty than the fresh water injected into formations during hydraulic fracturing. Also, the type and amount of clay groups and subgroup in the shale play an important role in distinguishing different hydrological behaviors of the rock. This is a result of where the charge deficiency is located (silica tetrahedral or alumina octahedral sheet), as well as of a continuous charge in shale pore pressure and composition [1].

Clay minerals are classified as 'silicates' but their chemical compositions typically have more oxygen than $\mathrm{Si}, \mathrm{Al}$, or $\mathrm{Mg}$, so many arguably consider them as (hydr)oxides of silicon, aluminium, or magnesium [2]. Shale rocks predominantly composed of clay such as kaolinite, smectite, and illite. They might also have other silica and carbonate based minerals that contribute to their geomechanical strength. Ian C. Bourg documented different shale rock formations showing the relationship between their utility and composition. Clay mineral content was identified as a very important variable that controls key material properties of these formations. Shale formations with high clay content (> 35\%) are utilized as seals for carbon capture and storage (CCS) and nuclear waste storage because of their low permeability and resilience to the formation of fractures [3].

\section{MATERIALS}

The Marcellus shale is found in the Appalachian Basin of eastern North America. Like most Devonian Appalachian shales with more than $2 \%$ (by volume) of organic materials, it tends to be black and classified as shales/mudrocks. These Black shales can contain more 
than $20 \%$ percent (by volume) of organic material, with organic carbon totaling up to 20 weight percent of the rock [4]. This late Devonian was formed in an oxygen-poor marine condition that resulted in the deposition of a dark mud and anoxic environment. It is part of the Hamiliton Group [5]. Black shales often are enriched with redox-sensitive metals and have varying solubilities under different oxygen levels - i.e. some have higher solubility in high oxygen environments than low oxygen environments and vice versa. It has been estimated that the metal enrichment in the Marcellus shale was formed roughly 400 million years ago and this created conditions of metal enrichment based on water chemistry and oxygen level [6].

The Marcellus Shale is made of dark-gray to black, fissile, pyritic shale. It is interbedded with dark-gray argillaceous limestone or calcareous shale [7]. Some areas also contain a fossiliferous layer of limestone which is the Purcell Member of the Marcellus Shale [7], and prominent zones of calcareous concretions ranging in diameter from several centimeters to more than $1 \mathrm{~m}(3.3 \mathrm{ft})$. The clay minerals in this Devonian-aged shale from the Appalachian basin are illite, chlorite, kaolinite, and two types of mixed-layer clay. Mixed-layer clay minerals result from the random interlayering of two or more clay minerals, including random interlayering of illite and an expandable mineral such as smectite, (called illite-smectite mixed-layer clay) and a random mixture of illite and either a degraded chlorite or a vermiculite [8].

The Marcellus formation has an especially interesting shale rock because not only it is considered for carbon capture and storage (CCS) compatibility, but regarding the latest advances in hydraulic fracturing technology, it can be used in the production of natural gas. The core samples used in this experiment are from an active production well in Washington County, PA, U.S. from depths of 6,300-6,450ft as shown in Fig. 1.

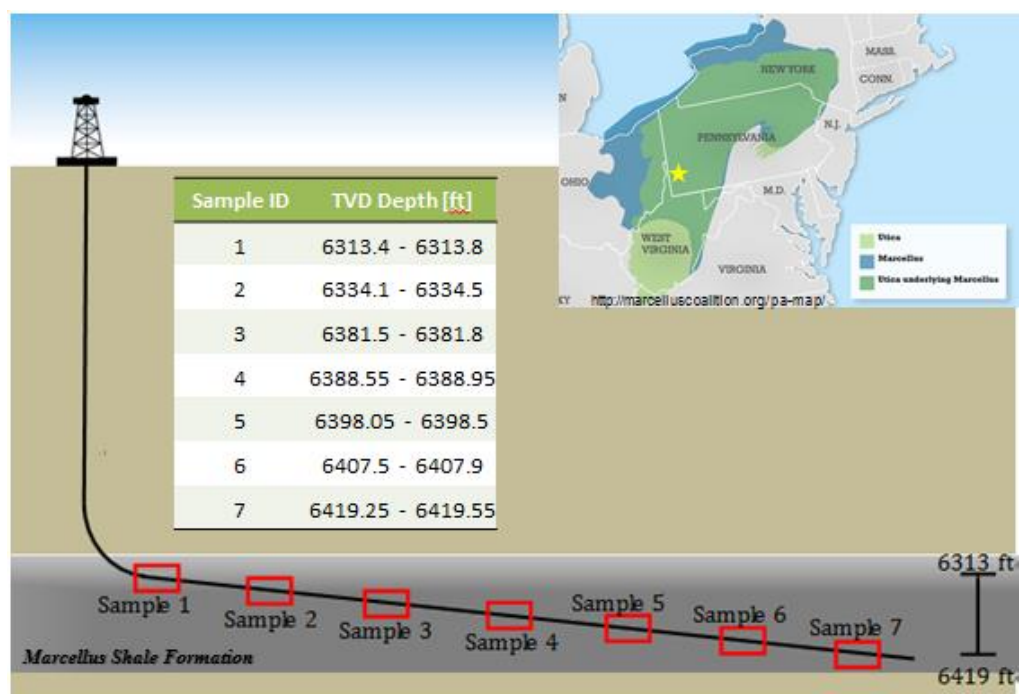

Fig. 1 Schematic of the well profile and the core samples ID and their corresponding depths. The bulk size of each core was about 4 inch in diameter and 1inch thick 


\section{MethodOLOGY}

\subsection{Sample preparation}

Six Marcellus shale samples are tested in this study including one outcrop and five core samples from an active production well. All of the samples are cut with a diamond saw into a small piece with approximately $1 \times 1$ inch in size and the thickness around 0.5 inch. Then specimen was then grinded, polished down to $1 \mu \mathrm{m}$ and ultrasonic cleaned. Finally, the specimen was oven dried for at least 24 hours to avoid the difference caused by moisture content.

\subsection{Micro and nano- indentation}

Micro indentation gives the average mechanical properties over the large area of different grains while nano-indentation could give the localized mechanical properties of a single grain. For the indentation tests, the indenter tip with a known geometry (Vickers Diamond) is driven into a specific site of the sample to be tested, by applying an increasing normal load. After reaching a pre-set maximum value, the normal load was paused for few seconds, then reduced until complete relaxation occurs. During the loading-unloading process, the position of the indenter relative to the sample surface is precisely monitored with an optical non-contact depth sensor. For each loading-unloading cycle, the applied load value versus position of the indenter was plotted. Hardness and elastic modulus are determined through load-displacement curve using Oliver \& Pharr's method [9]. The Schematic of indentation apparatus is shown in Fig. 2 and the basic parameters used are shown in Table 1.

\subsection{Scanning Electron Microscopes (SEM)}

For SEM imaging, the rock samples were first vacuumed and then sputter coated with $6 \mathrm{~nm}$ thick carbon. The microscope used for obtaining the SEM images was FEI Quanta 3D FEG dual beam FIB/SEM system at $20 \mathrm{kV}$. High resolution microscopy offered an insight into sample microstructure at micro to nanometer scale.
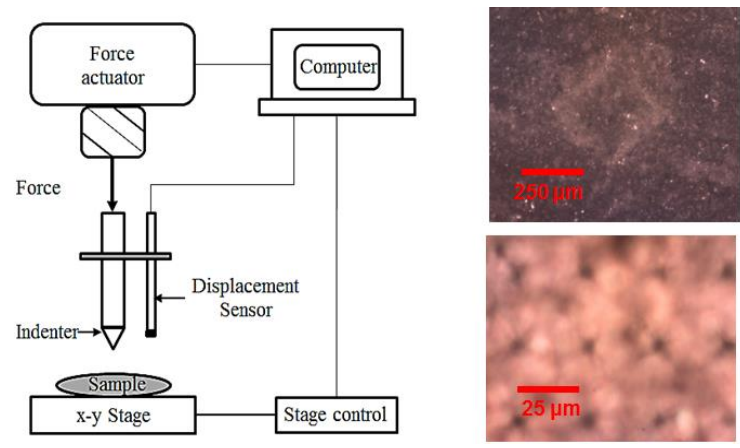

Fig. 2 Left: schematic of indentation apparatus; Right top: Single micro indentation mark, approximately $250 \times 250 \mu \mathrm{m}$ in area and $50 \mu \mathrm{m}$ in depth; Right bottom: nano indentation grid, each point is approximately $4 \times 4 \mu \mathrm{m}$ in area and 1 to $4 \mu \mathrm{m}$ in depth and distance between two points is 20 to $25 \mu \mathrm{m}$ 
Table 1 Setting conditions for micro and nano indentation

\begin{tabular}{lcc}
\hline & Micro & Nano \\
\hline Maximum force & $10(\mathrm{~N})$ & $50(\mathrm{mN})$ \\
Loading rate & $20(\mathrm{~N} / \mathrm{min})$ & $100(\mathrm{mN} / \mathrm{min})$ \\
Unloading rate & $20(\mathrm{~N} / \mathrm{min})$ & $100(\mathrm{mN} / \mathrm{min})$ \\
Pause at maximum load $(\mathrm{s})$ & 30 & 10 \\
Contact load (mN) & 15 & 0.08 \\
Poisson's ratio & 0.2 & 0.2 \\
Indenter type & Vickers & Vickers \\
\hline
\end{tabular}

"Poisson's ratio was assumed to be constant at 0.2 for simplification

\section{RESUlTS AND DISCUSSION}

\subsection{Microstructure of the Rock}

Optical microscopy images of the outcrop sample showing a minimum fracture of all samples, as for the deep cores and the amount of fractures increased as the depths increase. The cores samples are not completely representative of the in-situ condition as they are taken into the surface condition and oven dried, release of the overburden pressure amplified the fractures, shrinkage of the swelling clays could also contribute to the development of fractures, even so, these pictures still indicated the higher stiffness at the top portion of the formation than the bottom portion, as it maintains better integrity.

Optical images were taken of the samples before indentation was performed. These images are shown in Fig. 3. It is easy to see differences in fracture widths and basic compositional lamination differences.

The SEM analysis of the samples highlights major differences in textures, composition, and fracture sizes. Fig. 4 shows a micrograph of the outcrop and core Sample 2 at a $200 \mu \mathrm{m}$ scale. Fig. 5 shows a comparison of the outcrop and core Sample 7 at $100 \mu \mathrm{m}$.

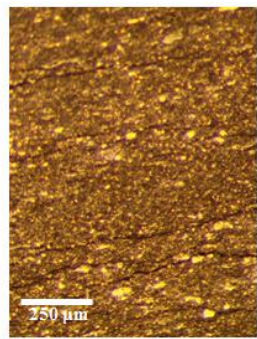

Outcrop

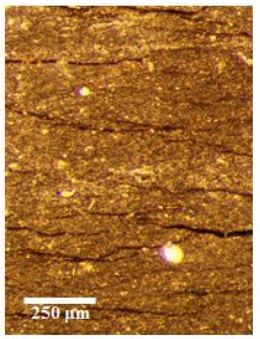

Core 2

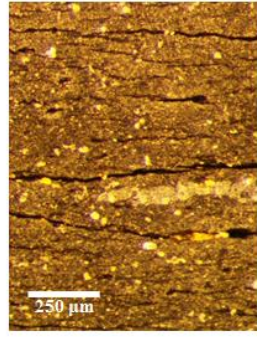

Core 4

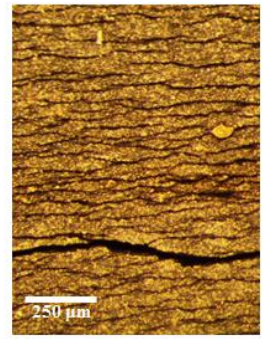

Core 7

Increasing of depths

Fig. 3 Optical microscopy images of samples cross-sections showing the fractures along the bedding. Outcrop sample has minimum amount of fractures, as the depths increase both the number and width of fractures increases 

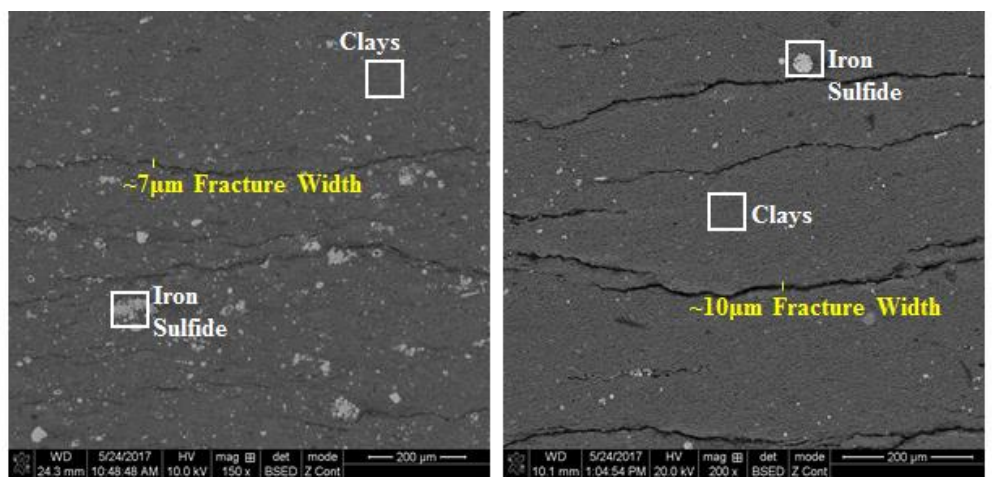

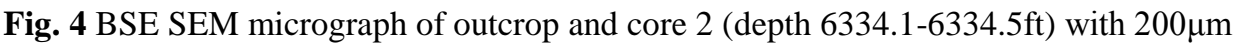
scale; Fracture width on the outcrop is slightly smaller than on the core sample 2; outcrop fracture width averages around $7 \mu \mathrm{m}$, while sample 2 fracture width averages around $10 \mu \mathrm{m}$
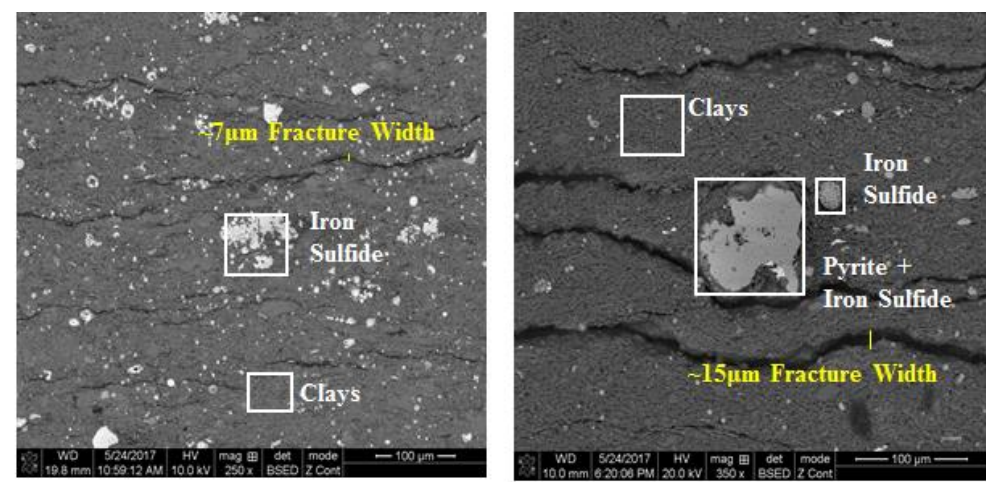

Fig. 5 BSE SEM micrograph of outcrop and core 7 (depth of 6419.25-6419.55ft) with $100 \mu \mathrm{m}$ Scale; The number of fractures on core 7 is significantly higher than the outcrop, also the average fracture width is much larger ( $15 \mu \mathrm{m}$ compared with $7 \mu \mathrm{m})$

From the SEM micrographs, outcrop sample has a lot more iron sulfide pockets than on both of the core samples, and the average fracture width increases as the depth increases. The larger fractures in the deeper samples indicate that they most likely have lower mechanical properties as the depth increases, which is also verified in the following experiment.

\subsection{Micro indentation}

Results from micro indentation (Fig. 6) showed the outcrop has overall higher mechanical properties, while within the same formation, the mechanical properties have a decreasing trend as the depth increased. The significant difference in mechanical properties between top and bottom portions of the formation can result in different fracture responses because mechanical properties of the rock are the key factor for determining the likelihood of fractures initiating and propagating. 
Based on the results, the bottom portions of the formation are more likely to start fractures as they are less mechanically stable, but with softer grains, the fractures are likely to heal faster at subsurface condition. For the top portion, higher stress is required for fracture initiation, once fractured, and grains with higher hardness behave more rigid which will help to support the open fractures.

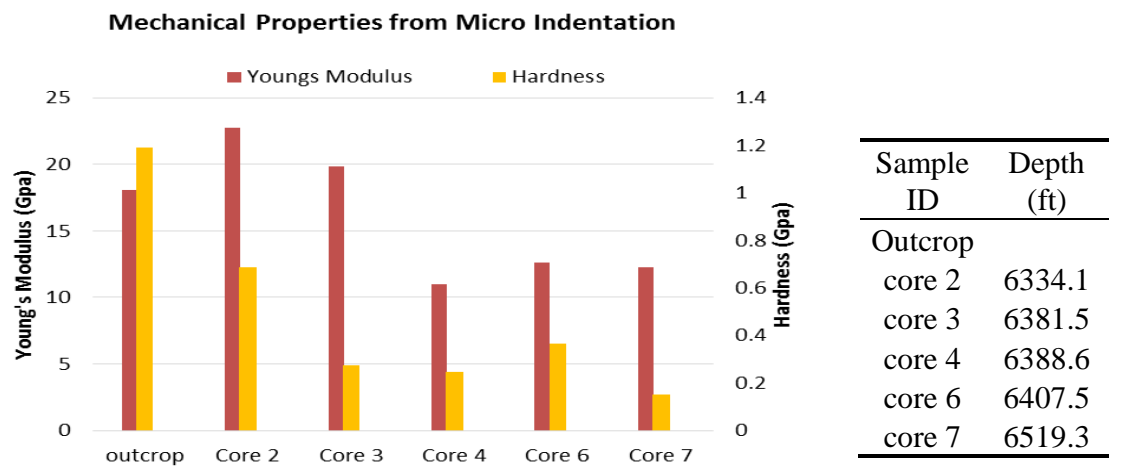

Fig. 6 Mechanical properties of Marcellus shale outcrop and cores measured by micro-indentation and their corresponding depths

\subsection{Nano indentation}

Nano indentations were done on both outcrop and core 3 , and the results are plotted in Fig. 7. The yellow spots represent grains with higher mechanical properties, which clearly showed more in outcrops hardness map. These rigid grains were evenly distributed which ends up an overall higher bulk hardness as shown in the result from micro indentation (Fig. 6). The Young's Modulus maps are relatively close comparing with the hardness maps because the calculation of hardness is based on plastic deformation of single grain, while the Young's modulus is always a composite response from all surrounding phases.

From the E distribution maps shown in Fig. 8, both samples have a large portion of data points laid in the range of clay minerals of kaolinite, smectite and illite while the outcrop may have higher quartz and mica content. The outcrop sample also has some high E grains, which could be chlorite or metal oxide.

Clay minerals have layered structures which often carry negative surface charges, which adsorb and hold cations by electrostatic force forming a double layer. The cation exchange capacity (CEC) of shale is proportional to its clay content, and has been shown to be related with its geomechanical properties [10]. The existence of this double layer can also reduce effective porosity, resulting in a decrease in permeability. The thickness of the double layer is dominated by the clay mineralogy, increasing from chlorite to kaolinite to illite to smectite, it is also influenced by salt concentration of the pore fluid [11]. Therefore, the type and amount of clay content are the key factors affecting shale sealing capacity, as both of them control the $\mathrm{CEC}$ which determines the mechanical and petrophysical properties of the rock. 

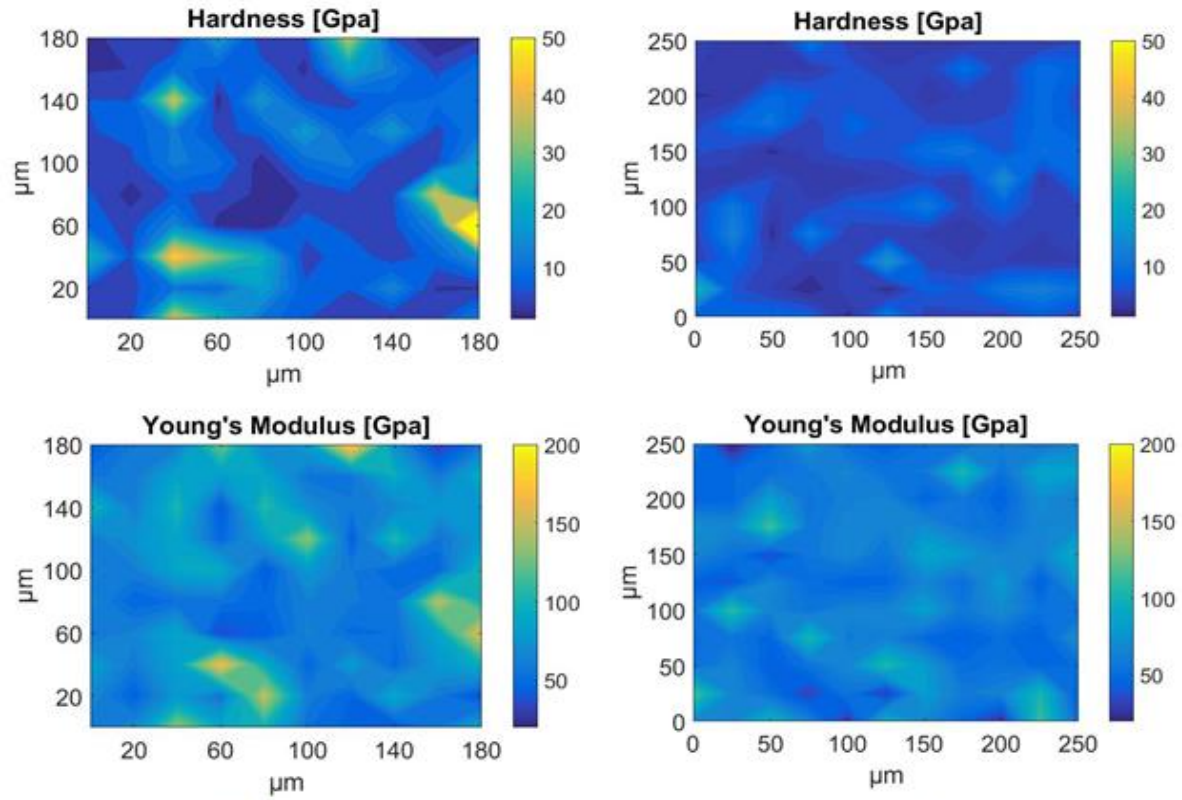

Outcrop

core3

Fig. 7 Mechanical properties maps of Marcellus shale rock outcrop (left) and core3 (right) based on 100 nano-indentation test results (10x10 grid)

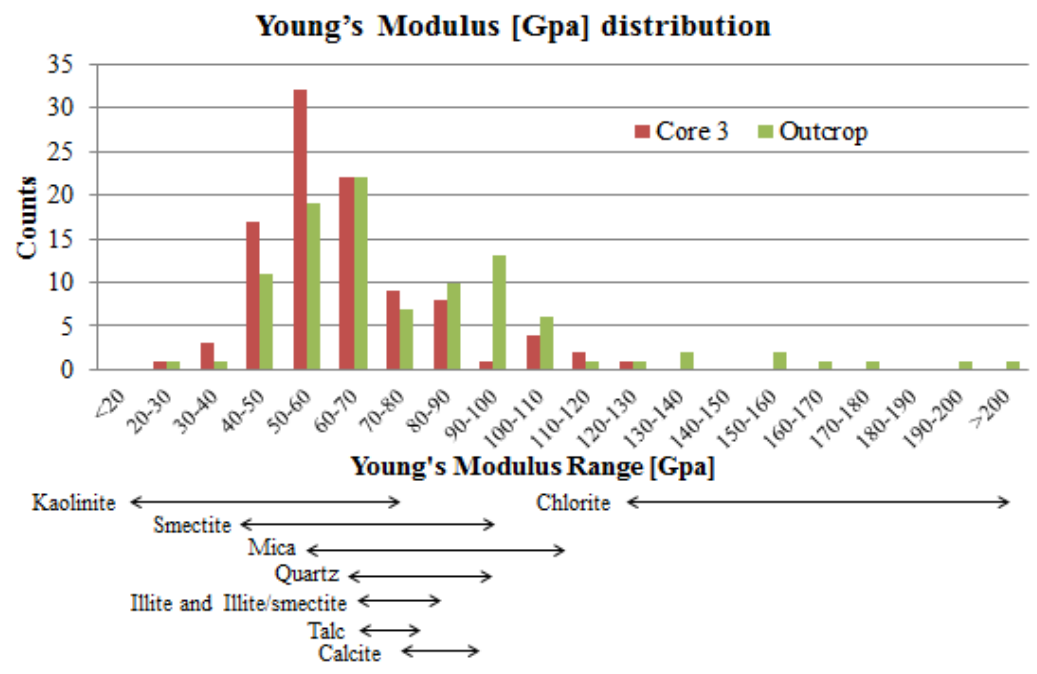

Fig. 8 Young's Modulus (E) data distribution of outcrop and core 3 measured by nano-indentation compared with literature $\mathrm{E}$ data $[12,13,14]$ of common minerals found in shale rocks 
The properties of clay mineral from the literature have much wider ranges due to the properties anisotropy caused by its platy microstructure. Progressive burial of the sediments caused mechanical compaction during the deposition, clay platelets are forced towards a parallel bedding alignment, with a rapid reduction of porosity and permeability, created layered structured shale rock $[15,16,17]$. From the micrometer size platy grains to meso-/ marco- scale layered rock, the significant anisotropy of properties were inherited.

\section{CONCLUSIONS}

Nano indentation could be an excellent two-dimensional mapping tool for examining the properties of constituent phases independently of each other in composite material microstructures. Mechanical maps could be used for correlating individual phase properties with bulk response.

Mechanical maps could be used for correlating individual phase properties with bulk response measured by micro indentation. Combing the mechanical properties map with high resolution microscopy (SEM), the mineralogy/morphology can be also correlated. The mechanical properties map can be also done on other multiphase composite such as cement to study the intrinsic properties of each component, as well as the interaction and properties of the bond and interfacial regions of different phases. It might also be useful for modeling the rock/cement behavior to predict the fracture occurrence potential, as it linked the microstructural features with their mechanical properties.

Acknowledgements: The authors would like to thank the Shared Instrument Facility (SIF) at Louisiana State University for the imaging. Dr. Vidic and Dr. Hill kindly provided samples. We would also like to thank the support from Sustainable Energy\& Environmental Research (SEER) lab in Louisiana State University

\section{REFERENCES}

1. Diaz-Perez, A., Cortes-Monroy, I., Roegiers, J.C., 2007, The role of water/clay interaction in the shale characterization, Journal of Petroleum Science and Engineering, 58(1-2), pp. 83-98.

2. Bergaya, F. and Lagaly, G. (Eds.), 2013, Handbook of Clay Science, Volume 5, $2^{\text {nd }}$ Edition, Elsevier, Amsterdam, Netherlands.

3. Bourg, Ian C., 2015, Sealing Shales versus Brittle Shales: A Sharp Threshold in the Material Properties and Energy Technology Uses of Fine-Grained Sedimentary Rocks, Journal of Environmental Science \& Technology Letters, 2(10), pp. 255-259.

4. Ettensohn, F.R., and Barron, L.S., 1982, A tectonic-climatic approach to the deposition of the Devonian-Mississippian black-shale sequence of North America; Proceedings of the 1982 Eastern oil shale symposium: Proceedings - Eastern Oil Shale Symposium, v. 1982, pp. 5-37.

5. Fisher, G. W., Pettijohn, F. J., Reed Jr., J.C., and Weaver, K. N. (Eds.), 1970, Studies on Appalachian Geology: Central and Southern, Interscience (Wiley), New York, US, p. 460.

6. Lee Avary, K., The Geology of the Marcellus Shale, available online: http://www.wvgs.wvnet.edu/www/ datastat/WVGES_GeologyMarcellusShale.pdf (Last access: 01.06.2017)

7. Cate, A.S., 1963, Lithostratigraphy of some Middle and Upper Devonian rocks in the subsurface of southwestern Pennsylvania, in Shepps, V.C. (Ed.), Symposium on Middle and Upper Devonian stratigraphy of Pennsylvania and adjacent states: Pennsylvania Geological Survey General Geology Report, 4th series, no. 39, pp. 229-240. 
8. Hosterman, J.W., Whitlow, S.I., 1983, Clay Mineralogy of Devonian Shales in the Appalachian Basin, Geological Survey Professional Paper 1298, United States Government Printing Office, Washington, 31p.

9. Oliver, W. and Pharr, G., 1992, An improved technique for determining hardness and elastic modulus using load and displacement sensing indentation experiments, Journal of Materials Research, 7(6), pp. 1564-1583.

10. Dewhurst, D.N., Siggins, A.F., Kuila, U., Clennell, M.B., Raven, M.D., Nordgård-Bolås, H.M., 2008. Elastic, geomechanical and petrophysical properties of shales, Proceedings of American Rock Mechanics Association Symposium. Paper ARMA 08-208, 12p.

11. Mesri, G. and Olson, R.E., 1971, Mechanisms Controlling the Permeability of Clays, Clays and Clay Minerals, 19, pp. 151-158.

12. Wang, Z., Wang, H., and Cates, M.E., 2001. Effective elastic properties of solid clays. Geophysics, 66, 428-440.

13. Mondol, N.H., Jahren, J., Bjorlykke, K., and Brevik, I., 2008, Elastic properties of clay minerals, The Leading Edge, 27, pp. 758-770.

14. Pawley, A.R., Clark, S.M., and Chinnery, N.J., 2002, Equations of state measurements of chlorite, pyrophyllite, and talc, American Mineralogist, 87(8-9), pp. 1172-1182.

15. Dewhurst, D.N., Aplin, A.C., Sarda, J.-P. and Yang, Y., 1998, Compaction-driven evolution of porosity and permeability in natural mudstones: An experimental study, Journal of Geophysical Research: Solid Earth,103, pp. 651-661.

16. Dewhurst, D.N., Aplin, A.C. and Sarda, J.P., 1999, Influence of clay fraction on pore-scale properties and hydraulic conductivity of experimentally compacted mudstones, Journal of Geophysical Research, 104(B12), pp. 29261-29274.

17. Yang, Y. and Aplin, A.C., 2007, Permeability and petrophysical properties of 30 natural mudstones, Journal of Geophysical Research, 112(B3), B03206. 